\title{
The Spillover Effect of Labor Agglomeration on Regional Economic Growth
}

\author{
Yunfei Ding \\ SHU-UTS SILC Business School, Shanghai University, Shanghai 201800, China \\ 860255154@qq.com
}

\begin{abstract}
Under the background that China's labor force is decreasing and they can move freely, this paper selects the Spatial Doberman model with time-individual fixed effects to analyze and study the spatial spillover effect and its impact mechanism of the labor agglomeration of 31 provinces in mainland China from 2003 to 2018 on regional economic growth. It was found that in China, the increase in the concentration of labor in a region and surrounding areas can promote economic growth in the region through the increase in marketization and the decline in the dependency ratio. However, the current regional economic growth in China is manifested by the promotion of labor agglomeration in the region and the suppression of labor agglomeration in the surrounding areas.
\end{abstract}

Keywords: Spatial Dubin Model; Labor Agglomeration; Regional Economic Growth.

\section{Introduction}

The 19th National Congress of the Communist Party of China pointed out that the main contradiction in the new era has been transformed into a contradiction between the people's growing need for a better life and unbalanced and inadequate development. Obviously, the unbalanced regional development has become the main contradiction, and the problems caused by the migratory bird migration of the labor force have gradually become prominent.

Therefore, trying to explore how labor agglomeration affects local and surrounding economic growth under China's national conditions is of great and far-reaching significance for enabling labor to better serve China's regional economic growth, promoting the overall rapid economic growth, and achieving the country's prosperity and strength.

\section{Text}

\subsection{Literature Review}

As the most basic element of material production, labor force will naturally affect economic growth. From Ricardo's labor theory of value to the Harold-Domar model and the Solow model, the labor force has always been regarded as the most basic and non-negligible element that affects the economic growth of a country or region. From 1980 to 2010, the growth of labor productivity and the slowdown of labor force growth in the United States brought about a decrease in the growth rate of per capita gross domestic product (GDP) [1]. In response to the fact that the number of labor force in China has been declining since 2011, Lin Ling and Wang Cheng simulated and analyzed the GTAP model and found that the decrease in labor force will reduce my country's welfare level, GDP and residents' income [2]. So, if the labor force is large, will it promote economic growth?

Industrial location economist Weber first proposed the concept of agglomeration, and the largescale free flow of labor is bound to bring about agglomeration. Martin \& Ottaviano proposed that the growth of economic activity and geographic agglomeration are mutually self-reinforcing processes [3]. Ciccone also found that the agglomeration of labor in Europe and the United States promotes economic growth, but the agglomeration effect in Europe is slightly smaller than the agglomeration effect in the United States [4]. But Krugman thinks that the agglomeration of labor can be catastrophic [5]. Through empirical research, Wang Jingwen and Wang Mingyan found that the spatial agglomeration of labor has an "inverted U"-shaped nonlinear effect on economic growth [6]. It can 
be seen that there is not a single linear relationship between the agglomeration of labor and economic growth.

In order to accurately study the relationship between labor agglomeration and economic growth, we will now discuss it from three perspectives: the transaction market, the labor market, and the age structure of the population. Once the labor force is concentrated, the market's micro-components population, purchasing power and purchasing desire will be formed. Fan Gang et al. found that from 1997 to 2007, the contribution of marketization index to economic growth reached an average annual rate of 1.45 percentage points [7]. However, the increase in prices and the increase in residents' living burdens brought about by active market transactions cannot be ignored. Zhang Haifeng et al. used the 2014 national migrant population dynamic monitoring data and 264 city characteristics data to study the impact of housing costs on labor mobility decisions, and found that the increase in urban housing costs as measured by the rent-to-income ratio significantly reduced the inflow of urban labor Probability [8]. The increase in the residents' living burden is bound to be detrimental to economic growth. According to the jungle rule of survival of the fittest, the accumulation of labor in a region will bring about an increase in the human capital stock of the labor market in that region. Baldwin \& Martin found that the relationship between growth and agglomeration mainly depends on the mobility of human capital or material capital between regions [9]. Barro believes that the growth rate of per capita GDP is positively correlated with human capital [10]. Wang Yue and Ma Shucai directly aimed at the economic growth effect of "polarization" of the labor force in my country, and found that the proportion of China's high-skilled labor force has a significant promoting effect on economic growth, but the proportion of low-skilled labor force has a significant inhibitory effect on economic growth [11]. However, Nicet-Chenaf \& Rougier found that: In developing countries, the increase in human capital may not promote GDP growth due to improper matching [12]. The traditional theory believes that if labor is concentrated in a region, the dependency ratio of the population will be low, and the burden will be less. When the income and prices remain unchanged, more consumption can be satisfied, so that the labor's enthusiasm for work will increase, thereby promoting economic growth. increase. However, Zhao Guoqing and Yao Qingsong found that my country's child dependency ratio has continued to decline since the 1980s, while the elderly dependency ratio has slowly increased, which ultimately promoted my country's economic growth [13]. The reason lies in the fact that my country's child population has the strongest spending power, the adult population is in the middle, and the elderly population has the weakest spending power. Therefore, the decline in the child dependency ratio and the increase in the elderly dependency ratio increase the per capita savings of residents and ultimately promote economic growth.

Anselin once proposed that certain economic characteristics in a regional geographic space unit are related to the economic characteristics of its neighboring areas [14]. And some studies have found that while manufacturing agglomeration promotes the economic growth of the province, it also has a positive spillover effect on the economic growth of neighboring provinces [15]. This provides an important idea for this study, and labor agglomeration should also have a certain impact on the economic growth of neighboring regions.

The existing research on the impact of labor agglomeration on the economy still has some shortcomings: First, when studying the relationship between the two in the past, the literature often ignores the intermediate variables such as the degree of marketization, the stock of human capital, and the dependency ratio of the population. Role, that is, lack of in-depth research on the mechanism of its influence. Second, most studies also focus on research in a certain area or as a whole, and lack consideration of spatial factors. The marginal contribution of this research lies in: incorporating geographic factors into the relationship between labor agglomeration and economic growth, and at the same time taking marketization, human capital stock and population dependency ratio as core explanatory factors, and interpreting China by constructing a spatial Dubin model. The logical relationship and spatial spillover effects between the agglomeration of labor and economic growth. 


\subsection{Models and Methods}

\subsubsection{Moran Index}

Generally speaking, it is impossible for a region to be completely independent from its surroundings, and there will be some exchanges more or less. As Tobler's "The First Law of Geography" describes it: everything is related to other things, but things near are more relevant than things far away [16]. In this paper, in order to study the autocorrelation relationship in the region and verify whether the spatial measurement model can be used, it is necessary to use the Moran index to test. The calculation expression of the global Moran index is as follows [17]:

$$
I=\frac{n \sum_{i=1}^{n} \sum_{j=1}^{n} w_{i j}\left(x_{i}-\bar{x}\right)\left(x_{j}-\bar{x}\right)}{\left(\sum_{i=1}^{n} \sum_{j=1}^{n} w_{i j}\right) \sum_{i=1}^{n}\left(x_{i}-\bar{x}\right)^{2}}
$$

Among them, $\bar{x}=\frac{1}{n} \sum_{i=1}^{n} x_{i}, x_{i}$ and $x_{j}$ are the attributes of $i$ and $j$ respectively; $\mathrm{n}$ is the total number of regions in the region; $I$ is the global spatial autocorrelation coefficient, which The value is in the interval of $[-1,1]$, which is used to judge whether there is a spatial relationship in the per capita GDP. If $I$ is in $[0,1]$, it indicates that the attributes are spatially positively correlated, that is, the attributes of neighboring areas have a certain similarity. If $I$ is located at $[-1,0]$, it means that the attributes are negatively correlated in space, that is, the attributes of the surrounding area are opposite to the local attributes.

\subsubsection{Models}

After reading the literature, I found that most of the predecessors studied the impact of agglomeration on the economy based on the Cobb-Douglas production function (C-D function) to build models. Therefore, this article also studies the impact of labor agglomeration on economic growth based on the C-D function.

When only capital and labor are considered as economic factors, the general form of the C-D function is:

$$
y=A L^{\alpha} K^{\beta}
$$

In the formula, $y$ is the total output, $A$ is the comprehensive technical level, $L$ is the labor force population, and $K$ is the invested capital. $\alpha$ represents the labor output elasticity coefficient, and $\beta$ is the capital output elasticity coefficient.

Take the logarithm of both sides and turn it into a linear function model:

$$
\ln y=\ln A+\alpha \ln L+\beta \ln K
$$

Among them, $\varepsilon$ is a random error term. In this paper, the labor concentration degree $J$ is used to replace the labor population $L$ as the core variable, the fixed asset investment of the whole society is used to represent the invested capital $K$, and the comprehensive technology level is replaced by the innovation level $A$ as the control variable. And introduce other control variables: the proportion of non-agricultural economy $E$, foreign trade situation $X$ and fiscal expenditure situation $G$. Get the general model:

$$
\ln y=\beta_{1} \ln J+\beta_{2} \ln A+\beta_{3} \ln K+\beta_{4} \ln E+\beta_{5} \ln X+\beta_{6} \ln G+\varepsilon
$$

$\beta_{1}, \beta_{2}, \beta_{3}, \beta_{4}, \beta_{5}, \beta_{6}$ are regression coefficients, which represent the influence of each explanatory variable on per capita GDP. 
In order to study the spatial spillover effect of labor agglomeration on regional economic growth, a spatial lag model (SLM), a spatial error model (SEM) and a spatial Dubin model (SDM) were established based on this model.

\subsection{Data}

\subsubsection{Research Area}

The regions studied in this article are 31 provinces in Mainland China from 2003 to 2018. The reason why we chose these 31 provinces and ignored Hong Kong, Macau, and Taiwan is because the systems in these regions are consistent, and there is no need to consider the influence of the political system of one country, two systems, that is, the research in this article controls the system factors. The time period from 2003 to 2018 was chosen because China's economy has also developed rapidly in this period of time into the new century, the market economy system has become more and more perfect, transportation has become more convenient, and the labor market has become more active than ever before. Rising wages have prompted more rural labor to flow into cities, and the continuous expansion of higher education has enabled more labor to stay in developed cities, which in turn has brought about the agglomeration of labor. It is more meaningful to study this period of time.

\subsubsection{Variable}

The level of economic growth y is the explained variable. This article uses the per capita GDP of each province in the National Statistical Yearbook to measure it. In view of the existence of the impact of inflation, the price level will affect the comparison of GDP in different years, so constant prices, that is, 2003 as the base period, are used to calculate the per capita GDP.

The core explanatory variables include labor agglomeration degree $\mathrm{J}$, the interaction term of labor agglomeration and marketization degree, the interaction term of labor agglomeration and human capital stock, the interaction term of labor agglomeration and population dependency ratio.

In accordance with international general standards, this article sets the labor force as a population between 15 and 64 years old. Since the degree of labor agglomeration reflects the degree of agglomeration of the labor population in a region relative to the labor population of the country, it is calculated by using the method of Liu Ruiwen et al. to calculate the degree of population agglomeration [18], that is, the proportion of the labor population in the region is compared with the labor population in the country. It is expressed as the ratio of the proportion of the land area of the region, and the calculation formula is as follows:

$$
J_{i}=\frac{\left(L_{i} / L_{n}\right) \times 100 \%}{\left(A_{i} / A_{n}\right) \times 100 \%}
$$

In the formula, represents the labor concentration in area $\mathrm{i}$, represents the labor population in area $i$, represents the land area in area $i$, represents the total labor force in the country, and represents the total land area in the country. Since the country does not have accurate statistics on the labor force population, the labor force population proportion surveyed in a region is used instead of the labor force population proportion of the region.

The stock of human capital is expressed by the average years of education of residents [19]. The population dependency ratio is the ratio of the number of children and the elderly to the number of working-age population.

Among the control variables, the level of innovation is expressed by the number of patents granted per capita, the investment in fixed assets of the whole society is measured by the proportion of fixed asset investment in the gross output value of the whole society, and the proportion of the nonagricultural economy is measured by the output value of the secondary and tertiary industries in the gross product value. The foreign trade situation is expressed by the total import and export of foreigninvested enterprises in the region as a percentage of the regional GDP, and the fiscal expenditure status is expressed by the proportion of fiscal expenditure in the GDP. 


\subsection{Results}

\subsubsection{Correlation Analysis of Regional Economic Growth}

This paper selects the economic growth levels of 30 provinces and municipalities in mainland China from 2003 to 2018 to calculate the corresponding global Moran index and significance test results. The result found that the global Moran index is between 0.115 and 0.135 , and the $\mathrm{P}$ value is always less than 0.01 , so it has passed the significance test, that is, the economic growth levels of 31 provinces and municipalities have a strong positive spatial correlation. Therefore, neighboring regions often have similar economic growth levels, and regions with high economic growth levels tend to have higher economic growth levels in neighboring regions, so that spatially, the level of economic growth will form agglomerations.

\subsubsection{Choice of Spatial Measurement Model}

Regardless of spatial factors for the time being, for ordinary panel data, $R$ is used to compare and analyze the mixed estimation model (MEM), fixed effect model (FEM) and random effect model (REM). The results are shown in Table 1. In order to select the most suitable model, F-test is first used to judge whether the fixed effects model is better than the mixed estimation model. The result is that the $\mathrm{p}$ value is less than 0.05 . The alternative hypothesis has a significant effect, that is, the fixed effects model is better. Then use the Hausman test to compare the random effects model and the fixed effects model [20], and finally found that the $p$ value is less than 0.05 , so the null hypothesis of the random effects model is rejected, so the fixed effects model is better. Finally, the fixed effects model was chosen.

Table 1. Estimates of the common panel model

\begin{tabular}{|c|c|c|c|}
\hline Variable & MEM & FEM & REM \\
\hline \multirow{2}{*}{ Intercept } & $\begin{array}{c}4.507 * * * \\
(75.821)\end{array}$ & $\begin{array}{c}4.541^{* * *} \\
(82.661)\end{array}$ \\
\hline \multirow{2}{*}{$\ln J$} & $-0.0457^{* * *}$ & $0.323^{* * *}$ & $0.064^{* * * *}$ \\
& $(-5.491)$ & $(7.580)$ & $(3.988)$ \\
\hline R-Squared & 0.831 & 0.942 & 0.933 \\
\hline Adj. R-Squared & 0.830 & 0.938 & 0.932 \\
\hline F test & F $=88.326, p-$ value $=0.000$ \\
\hline Hausman test & \multicolumn{3}{|c|}{ Chisq $=57.573, p$-value $=0.000$} \\
\hline
\end{tabular}

In order to avoid the endogenous problem as much as possible, this article adopts time-point individual fixed effects. Using Matlab to obtain three spatial measurement models with individual fixed effects at time points are shown in Table 2. The goodness of fit $\mathrm{R}$-squared value and maximum likelihood log-likelihood value of the spatial Doberman model with time-point individual fixed effects are larger than the other two models, and the dispersion sigma^ 2 is relatively larger than the other two the model is smaller, so the spatial Doberman model with individual fixed effects at the time point fits the data better. And from the Dubin model with individual fixed effects at the time point, it can be known that the impact of labor agglomeration in a region on per capita GDP is significantly negative. The impact of GDP is significantly positive.

Next, this paper chooses the spatial Dubin model with individual fixed effects at the time point to specifically study the influence mechanism of labor agglomeration on per capita GDP. The regression results obtained are shown in Table 3. The increase in the degree of labor concentration in an area can promote the economic growth of the area through the increase in the degree of marketization and the decrease in the dependency ratio of the population. At the same time, the increase in the concentration of labor in the surrounding area of an area can also promote the economic growth of the area through the increase in the degree of marketization and the decrease in the dependency ratio of the population. It is just that the impact of human capital stock as an intermediate variable is not very significant, perhaps because the human capital stock does not match the industrial structure. 
Table 2. Spatial regression model with individual fixed effects at the time point

\begin{tabular}{|c|c|c|c|}
\hline Variable & SAR-FE & SEM-FE & SDM-FE \\
\hline $\ln J$ & $-0.028^{* * *}$ & $-0.028^{* * *}$ & $-0.019^{*}$ \\
& $(-3.591)$ & $(-3.485)$ & $(-1.960)$ \\
\hline$W^{*} \ln J$ & & & $-0.043^{*}$ \\
& & & $(-1.030)$ \\
\hline$W^{*} \ln A$ & & & $-0.213^{* *}$ \\
& & & $-1.366)$ \\
\hline \multirow{2}{*}{$W^{*} \ln K$} & & & $(-5.528)$ \\
\hline \multirow{2}{*}{$W^{*} \ln E$} & & & $-8.252^{* * *}$ \\
& & & $(-4.901)$ \\
\hline \multirow{2}{*}{$W^{*} \ln X$} & & & $0.105^{*}$ \\
& & & $(1.583)$ \\
\hline$W^{*} \ln G$ & & & 0.181 \\
& & & $(0.807)$ \\
\hline R-squared & & & 0.931 \\
\hline sigma^2 & 0.905 & 0.008 & 0.007 \\
\hline $\log$-likelihood & 437.686 & 466.617 & 500.011 \\
\hline
\end{tabular}

Table 3. The influence mechanism model of the spatial Dubin model

\begin{tabular}{|c|c|c|}
\hline Variable & Coefficient & Asymptot t-stat \\
\hline $\ln (J \times M)$ & $0.643^{*}$ & 1.258 \\
\hline $\ln (J \times H)$ & 0.117 & 0.374 \\
\hline $\ln (J \times R)$ & $-0.301^{*}$ & -1.635 \\
\hline $\ln J$ & 0.068 & 0.225 \\
\hline$W * \ln (J \times M)$ & $10.171^{* * *}$ & 4.267 \\
\hline$W * \ln (J \times H)$ & -0.336 & -0.204 \\
\hline$W * \ln (J \times R)$ & $-1.003^{*}$ & -1.137 \\
\hline$W * \ln J$ & $-4.097^{* *}$ & -2.783 \\
\hline$W * \ln A$ & $-0.809^{*}$ & -1.639 \\
\hline$W * \ln K$ & $1.137^{*}$ & 1.472 \\
\hline$W * \ln E$ & $6.151^{*}$ & 1.073 \\
\hline$W * \ln X$ & -0.049 & -0.219 \\
\hline$W * \ln G$ & -0.665 & -0.909 \\
\hline $\mathrm{R}$-squared & & \\
\hline sigma^2 & \multicolumn{2}{|c|}{0.919} \\
\hline
\end{tabular}

\subsubsection{Analysis of the Spillover Effect of Labor Agglomeration on Economic Growth}

The above-mentioned spatial Dubin model with fixed effect of time point and space is used to decompose the spatial effect of each factor through partial differentiation, and obtain the direct effect, indirect effect and total effect of each factor on labor agglomeration. Using Matlab to calculate the effect of each influencing factor on the decomposition of per capita GDP is shown in Table 4. In general, the direct effect of labor concentration in the region is 0.044 , the indirect effect is -4.476 , and the total effect is -4.432 . From the perspective of the impact mechanism, the increase in the per capita GDP of the region can be achieved through the increase in the level of marketization and the decrease in the dependency ratio of the population brought about by the agglomeration of labor in the region and surrounding areas. Among them, the increase in the level of marketization in the surrounding area and the decrease in the dependency ratio of the population can bring about an increase in the per capita GDP of the area, which reflects the economic spillover effect of the surrounding area on the region. 
Volume 13 (2021)

Table 4. Decomposition effects of spatial Doberman model based on individual fixed effects at time points

\begin{tabular}{|c|c|c|c|}
\hline Variable & Direct Effect & Indirect Effect & Total Effect \\
\hline \multirow{2}{*}{$\ln (J \times M)$} & $0.701^{*}$ & $11.144^{* * *}$ & $11.844^{* * * *}$ \\
& $(1.365)$ & $(3.918)$ & $-472)$ \\
\hline $\ln (J \times H)$ & 0.117 & -0.335 & $(-0.132)$ \\
\hline \multirow{2}{*}{$\ln (J \times R)$} & $(0.390)$ & $(-0.188)$ & $-1.417^{*}$ \\
& $-0.305^{*}$ & $-1.112^{*}$ & $(-1.609)$ \\
\hline $\ln J$ & $(-1.733)$ & $(-1.154)$ & $-4.432^{* *}$ \\
& 0.044 & $-4.476^{* *}$ & $(-2.832)$ \\
\hline
\end{tabular}

\section{Summary}

This article explores the spatial spillover effects of China's labor agglomeration on economic growth from 2003 to 2018, and draws the following conclusions:

The regional economy has spatial autocorrelation, and for regions with higher economy, the closer the surrounding area is to the region, the higher the economy. In China, a moderate increase in the degree of labor agglomeration in a region can promote an increase in the region's per capita GDP, but the degree of labor agglomeration in the surrounding areas of a region has a certain negative impact on the region's per capita GDP. In addition, the increase in the degree of marketization and the decrease in the dependency ratio of the population caused by the increase in the degree of labor concentration in the local and surrounding areas can promote the increase of the per capita GDP of the region.

Therefore, if a region is to develop, it needs to reasonably control the degree of labor concentration, so that labor and other resources can be reasonably allocated. Specifically, the scope of satellite cities can be expanded, the degree of marketization can be improved, and the social security system can be improved.

\section{References}

[1] Maestas, Nicole, Kathleen J. Mullen \& David Powell. The Effect of Population Aging on Economic Growth, the Labor Force and Productivity. National Bureau of Economic Research,2016.

[2] Lin Ling, Wang Cheng, the impact of labor reduction on my country's real economy--simulation based on GTAP model, Population and Economy,2014, (01): 80-87.

[3] Martin, Philippe \& Gianmarco I.P. Ottaviano. Growth and Agglomeration. International Economic Review, 2001, 42(4): 947-968.

[4] Ciccone, Antonio. Agglomeration Effects in Europe. European Economic Review,2002, 46(2): 213-227.

[5] Krugman, Paul. "Increasing Returns and Economic Geography." Journal of Political Economy,1991,99(3): 483-499.

[6] Wang Jingwen, Wang Mingyan. The impact of China's labor spatial agglomeration on economic growth. Economics and Management Research, 2019, 40(03):86-106.

[7] Fan Gang, Wang Xiaolu, Ma Guangrong, The Contribution of China's Marketization Process to Economic Growth, Economic Research, 2011,46(09):4-16.

[8] Zhang Haifeng, Zhang Jiazi, Yao Xianguo, The spatial evolution of housing costs in my country and the impact of labor mobility decision-making, Economic Geography, 2019,39(07): 31-38.

[9] Baldwin, Richard E. \& Philippe Martin. Agglomeration and Regional Growth. Handbook of Regional and Urban Economics. Elsevier,2004, 4: 2671-2711.

[10] Barro, Robert J. Economic Growth in a Cross Section of Countries. The Quarterly Journal of Economics, 1991, 106(2): 407-443.

[11] Wang Yue, Ma Shucai, Research on the Spatial Effect of China's Labor Force "Polarization" on Economic Growth, Management Modernization,2017, 37(02):107-111. 
[12] Nicet-Chenaf, Dalila \& Eric Rougier. Human Capital and Structural Change: How Do They Interact with Each Other in Growth? GRETHA UMR CNRS,2009, 5113.

[13] Zhao Guoqing, Yao Qingsong, Age structure and economic growth-theoretical framework and empirical analysis based on Chinese data, Shanghai Finance,2018, (03): 17-30.

[14] Anselin, Luc. Spatial Econometrics: Methods and Models. Springer Science \& Business Media,2013.

[15] Tang Jianrong, Fang Yuxiao, Zhang Xinhe, Tang Yuchen (2018), Research on the Spatial Spillover Effect of Industrial Agglomeration and Regional Economic Growth--Based on the Dubin Model of China's Provincial Manufacturing Space, Statistics and Information Forum, 33(10):56 -65.

[16] Tobler, Waldo R. A Computer Movie Simulating Urban Growth in the Detroit Region. Economic geography,1970, 46(sup1): 234-240.

[17] Fischer, Manfred M. A spatial Mankiw-Romer-Weil model: Theory and Evidence. The Annals of Regional Science, 2011, 47(2): 419-436.

[18] Liu Ruiwen, Feng Zhiming, You Zhen, Research on the Pattern and Formation Mechanism of China's Population Concentration, China Population, Resources and Environment,2010, 20(03):89-94.

[19] Psacharopoulos, George\& Ana Maria Arriagada. The Educational Composition of the Labour Force: An International Comparison. International Labour Review,1986, 125: 561.

[20] Wooldridge, Jeffrey M. Econometric Analysis of Cross Section and Panel Data. MIT press,2010. 